\title{
Cerebellopontine angle cavernous hemangioma
}

\author{
Mônica Porto Alves Alcantara ', Paulo Roberto \\ Lazarini ${ }^{2}$,José C. E. Veiga ${ }^{3}$, Erick S. Barboza ", \\ Carmen L. P. Lancellotti ${ }^{5}$
}

\section{INTRODUCTION}

Cavernous hemangioma, also known as cavernous angioma, accounts for 10-20\% of vascular malformations.1,2 Extra-axial lesions are rare. Most tumors are found in the sinuses, Meckel's cavity, posterior fossa, including the cerebellarpontine angle and internal auditory meatus.3

This paper reports the clinical case of a patient with cavernous hemangioma involving the internal auditory meatus whose initial diagnosis was vestibular schwannoma.

\section{CASE REPORT}

JMM, female, 51 years of age, Caucasian, born in Pernambuco, complained of humming in her right ear and of slow, progressing hearing loss, with both conditions afflicting her for the past three years. She also experienced sporadic dizzy spells when turning to the left in episodes that lasted for less than a minute, usually followed by nausea and often accompanied by louder humming and hearing loss.

Audiometric tests pinpointed deep right-ear sensorineural hearing loss

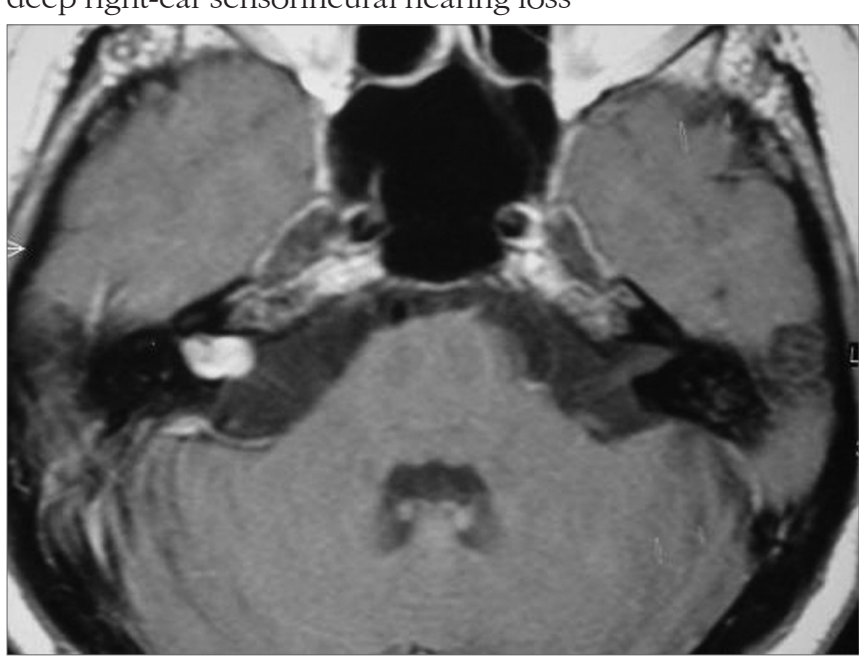

and mild left-ear hearing loss. Neuro-otologic tests suggested right-side vestibular deficit syndrome.

No changes were found in the cranial CT scan, both with and without enhancement. Skull MRI images showed a $1.2 \times 0.8 \mathrm{~cm}$ lobular structure expanding the right-side internal auditory meatus with a minor cisternal component, characterized by intermediate-level signal on T1, hypersignaling on T2 and impregnation by paramagnetic agent. (Figure 1)

The patient was submitted to a translabyrinthine approach on April 14 2004. The procedure had to be aborted due to intense intra-op bleeding when opening the dura. The patient was reoperated on April 16, 2004. This time the suboccipital approach was chosen and the tumor was removed.

The pathologist's report identified cavernous angioma with recent thrombosis.

\section{DISCUSSION}

In this case report a patient with cavernous hemangioma in the internal auditory meatus came to our service complaining of auditory loss accompanied by humming and sporadic dizziness. The patient's facial nerve was not involved. Even though some authors 4,5 claim this type of tumor often involves the nerve, the literature review done by Babu et al.1 concluded that peripheral facial palsy is not a frequent finding.

Asymmetric auditory loss and vestibular examination suggesting vestibular deficit syndrome led us to consider the presence of a tumor Figure 1. Skull MRI scan (axial T1 contrast-enhanced) showing right-side cavernous he- in the retro-cochlear mangioma.

MD, otorhinolaryngologist under training at the Otorhinolaryngology Department of the São Paulo Santa Casa Hospital.

${ }^{2} \mathrm{PhD}$, Instructor Professor at the Medical School of the São Paulo Santa Casa Hospital, Assistant Physician at the Otorhinolaryngology Department of the São Paulo Santa Casa Hospital. $\mathrm{PhD}$, Director of the Neurosurgery Department of the São Paulo Santa Casa Hospital area later visualized in MRI. It is worth that MRI is more sensitive and more specific than CT1,3,5. In our spite of the hemangioma in the patient's internal auditory meatus.

Differential diagnosis is important and includes mainly meningioma vestibular schwannoma, facial nerve schwannoma2,3,5,6 and lipoma.1

According to Pappas et al.1,2, schwannomas present intermediate signaling on T1 and hypersignaling on T2 with gadolinium uptake, as described by the radiologist in our case.

\section{CONCLUSION}

Cavernous hemangiomas in the internal auditory meatus are rare and be characterized by unilateral sensorineural auditory deficiency. MRI is the ique of choice to achieve differenial diagnosis. Final diagnosis can only be reached after pathology exam.

\section{REFERENCES}

Babu R, Ransohoff J, Cohen N, Zagzag D. Cavernous Angiomas of the Internal Auditory Canal. Acta Neurochir (Wien) 1994;129:100, Spetzler RF. Surgical Management of Cavernous Malformation Involving the Cranial Nerves. Neurosurgery 2003;53(2):352-7.

3.Kim M, Rowed DW, Cheung G, Ang L. Cavernous malformation presenting as an extraaxial Cerebellopontine Angle Mass: Case Report. Neurosurgery 1997;40(1):187-90

4.Hanamitsu M, Okomura K, Yazawa Y, Fukui J, Suzuki M. Cavernous haemangioma of the internal auditory canal: A case report. Cin Neurosci 2004;11(3):337-40.

.Omojola MF, Hawashim NS, Zuwayed M, Ferayan A.CT and MRI features of cavernous haemangioma of internal auditory canal. The Br J Radiol 1997;70:1184-7.

Fuzuda Y, Ganança FF, Nascimento LA, Testa R, Munhoz MS, Ganança MM, Mangabeira-Albernaz PL. Cavernous hemangioma of the internal auditory canal. A propos of the case. Rev Laryngol Otol Rhinol (Bord)1995;116(3):229-30

PhD, Associate Professor at the Pathology Department of the São Paulo Santa Casa Hospital.

Paper submitted to the ABORL-CCF SGP (Management Publications System) on March 9th, 2005 and accepted for publication on May 15th, 2006. cod. 48.
} 